\title{
Ion Velocity in the Discharge Channel and Near-Field of the HERMeS Hall Thruster
}

\author{
Wensheng Huang*, Hani Kamhawi ${ }^{\dagger}$, and Daniel A. Herman* \\ National Aeronautics and Space Administration Glenn Research Center, Cleveland, OH, 44135, USA
}

\begin{abstract}
NASA is continuing the development of a $12.5-\mathrm{kW}$ Hall thruster system, which is baselined in a phased exploration concept to expand human presence to cis-lunar space and eventually to Mars. The development team is transitioning knowledge gained from the testing of the government-built Technology Development Unit (TDU) to the contractor-built Engineering Development Unit (EDU). A new laser-induced fluorescence diagnostic that is compatible with the testing of engineering hardware was developed to obtain data for thruster model validation in the lowest background pressure achievable. Prior to performing the test on the EDU, the team performed a functional checkout test of this new diagnostic using the TDU. In addition to providing a checkout of the diagnostic, this test provided data that can be correlated to electron mobility for comparison to the EDU at a later date. A number of technical challenges related to large test facilities and interfacing with engineering hardware were overcome while implementing the new laser diagnostic system. The initial data set was in good agreement with prior optical and non-optical diagnostics data collected on the TDU thrusters. This data set also revealed the spatial origin of high angle ions that have been of concern for spacecraft integration.
\end{abstract}

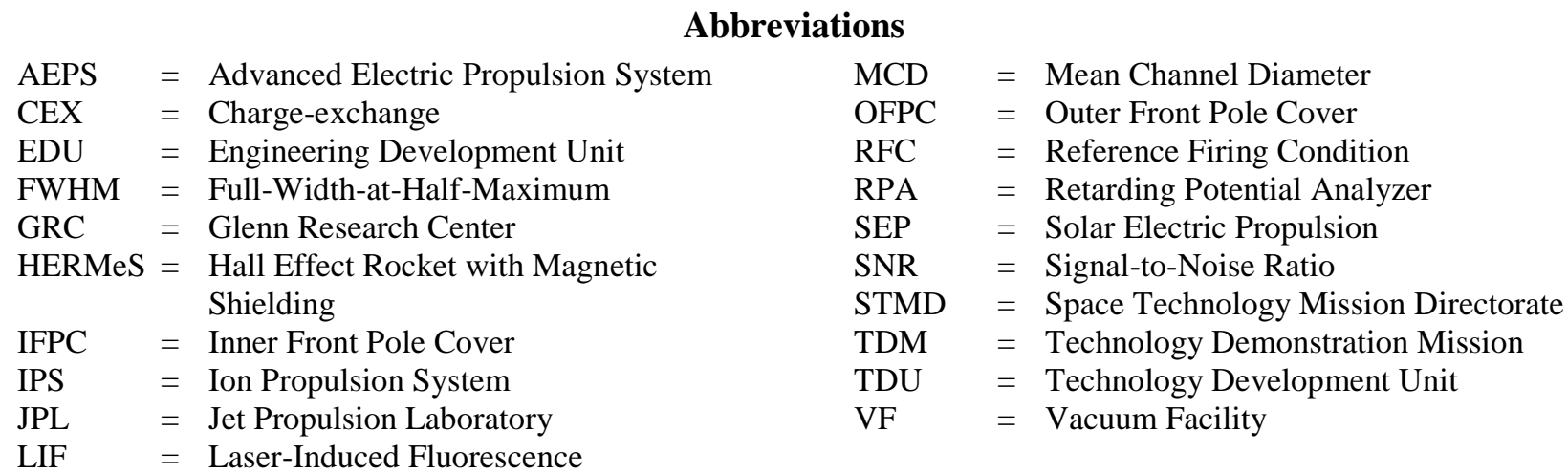

\section{Introduction}

$\mathrm{F}^{\mathrm{s}}$ OR missions beyond low Earth orbit, spacecraft size and mass can be dominated by onboard chemical propulsion systems and propellants that may constitute more than 50 percent of spacecraft mass. This impact can be substantially reduced through the utilization of Solar Electric Propulsion (SEP) due to its substantially higher specific impulse. Studies performed for NASA's Human Exploration and Operations Mission Directorate (HEOMD) and Science Mission Directorate have demonstrated that a $40 \mathrm{~kW}$-class SEP capability can be enabling for both near term and future architectures and science missions. ${ }^{1}$

Since 2012 NASA has been developing a high-power Hall thruster electric propulsion string that can serve as the building block for realizing a 40-kW-class SEP capability. NASA continues to evolve a human exploration approach to expand human presence beyond low-Earth orbit and to do so, where practical, in a manner involving

\footnotetext{
* Ion Propulsion System Diagnostics Lead, EP Systems Branch, wensheng.huang@ nasa.gov, Senior Member.

${ }^{\dagger}$ Ion Propulsion System Test Lead, EP Systems Branch, hani.kamhawi-1@nasa.gov, Associate Fellow.

* Ion Propulsion System Lead, EP Systems Branch, daniel.a.herman@ nasa.gov, Associate Fellow.
}

1

American Institute of Aeronautics and Astronautics 
international, academic, and industry partners. ${ }^{2}$ NASA publicly presented a phased exploration concept at the HEOMD Committee of the NASA Advisory Council meeting on March 28, 2017. ${ }^{3}$ NASA presented an evolutionary human exploration architecture, called Lunar Orbital Platform - Gateway, to expand human presence deeper into the solar system through a phased approach including cis-lunar flight testing and validation of exploration capability before crewed missions beyond the Earth-Moon system and eventual crewed Mars missions. One of the key objectives is to achieve human exploration of Mars and beyond through the prioritization of those technologies and capabilities best suited for such a mission in accordance with the stepping stone approach to exploration. ${ }^{4}$ Highpower solar electric propulsion is one of those key technologies that has been prioritized because of its significant exploration benefits. A high-power, $40 \mathrm{~kW}$-class Hall thruster propulsion system provides significant capability and represents, along with flexible blanket solar array technology, a readily scalable technology with a clear path to much higher power systems.

The Hall thruster system development, led by the NASA Glenn Research Center (GRC) and the Jet Propulsion Laboratory (JPL), began with the maturation of the $12.5-\mathrm{kW}$ Hall thruster and power processing unit. The technology development work has transitioned to Aerojet Rocketdyne via a competitive procurement selection for the Advanced Electric Propulsion System (AEPS). The AEPS contract includes the development, qualification, and multiple flight electric propulsion string deliveries. The AEPS Electric Propulsion string consists of the Hall thruster, power processing unit (including digital control and interface functionality), xenon flow controller, and associated intra-string harnesses. These components are also collectively known as the Ion Propulsion System (IPS). NASA continues to support the AEPS development leveraging in-house expertise, plasma modeling capability, and world-class test facilities. NASA also executes AEPS and mission risk reduction activities to support the AEPS development and mission application.

Risk reduction activities are being carried out on the precursor to AEPS known as the Hall Effect Rocket with Magnetic Shielding (HERMeS). ${ }^{5,}{ }^{6}$ The specifications for the $12.5-\mathrm{kW}$ HERMeS are enhanced compared to the current state of the art. ${ }^{5}$ Characteristics of the thruster include high system efficiency $(\geq 57 \%)$, high specific impulse (up to $3000 \mathrm{~s}$ ), and high propellant throughput capability (1770 kg). Additionally, HERMeS was designed to deliver similar system efficiency at a more modest specific impulse of 2000 seconds. High specific impulse operation supports mission concepts with high total-impulse requirements like deep-space exploration missions, while the modest specific impulse operation is beneficial for time-critical operations like LEO to GEO orbit raising.

A series of tests are being performed on three HERMeS Technology Development Units (TDUs). ${ }^{6}$ Figure 1 shows a diagram of the testing on the HERMeS TDUs thus far as well as tests that are planned. Testing on the TDU1 included the propellant uniformity test, ${ }^{7}$ magnetic shielding characterization test, ${ }^{8}$ performance characterization test, ${ }^{9-11}$ thermal characterization test, ${ }^{12,}{ }^{13}$ facility effect characterization test, ${ }^{9,11,14}$ and the first wear test campaign. The performance, thermal, and facility effect characterization tests were performed with a single test setup. The first wear test campaign, completed in 2016, included the electrical configuration characterization test, ${ }^{15}$ two short duration tests, ${ }^{16}$ and a long wear test. ${ }^{16,}{ }^{17}$ TDU2 underwent an acceleration zone characterization test $\mathrm{t}^{18}$ and a pole erosion Figure 1. A diagram of the TDU test campaign. characterization test. ${ }^{19}$ TDU2 is undergoing the environmental test campaign. TDU3 was used in a second performance characterization test ${ }^{20}$ and, together with TDU1, in a second wear test campaign. ${ }^{21}$

Additionally, GRC Vacuum Facility 6 (VF6) was reconfigured to reconstitute high-power electric propulsion testing capability, which was followed by a series of verification and validation tests to confirm facility readiness. ${ }^{22}$ VF6 was then used for parts of the second wear test campaign. ${ }^{21}$

During early risk reduction testing performed on the H6 Hall thruster, the plasma in the discharge channel was found to be strongly perturbed by the injection of physical probes into the discharge channel. ${ }^{23}$ The team decided to instead rely on non-invasive laser-induced fluorescence (LIF) techniques to obtain the discharge channel plasma data needed for model validation. A key driver of Hall thruster plasma dynamics is the spatial distribution of electron mobility, also called the mobility profile. Laser-induced fluorescence (LIF) velocimetry can measure 
velocity distribution functions, which can be correlated to the mobility profile and provide an effective assessment of any differences between the plasma dynamics of the EDU and TDU.

NASA GRC has developed a new LIF diagnostic system that is fully compatible with the testing of high-power engineering electric propulsion devices. The new laser diagnostic system was functionally checked during a test using TDU1 in VF6. The system was then used to study various test conditions. Regions of interest in the obtained data set include the main acceleration zone, nearchamfer regions, and near the pole covers of the thruster. The data set also covered different discharge voltages, magnetic field strengths, and background pressure. This paper will focus on the operating conditions spanning 300 to $600 \mathrm{~V}$ discharge voltage at nominal magnetic field and lowest background pressure. Additional data will be published in the future.

This paper will begin by discussing the experimental setup and technical challenges associated with implementing LIF in a large vacuum facility that interfaces with engineering hardware. The paper will then discuss data analysis and results from the LIF functional checkout test.

\section{Experimental Setup}

To simplify plot labeling, throttle points are labeled by discharge voltage and discharge power. A label that says "300-6.3" refers to the throttle point with a discharge voltage of $300 \mathrm{~V}$ and a discharge power of $6.3 \mathrm{~kW}$.

Unless otherwise noted, all spatial positions around the thruster are normalized based on the region of interest. For the thruster discharge channel, radial positions are normalized by the discharge channel width, where $R=0$ is the inner wall, $R=1$ is the outer wall, $\mathrm{Z}=0$ is the exit plane as defined by the inner front pole cover downstream surface, and $\mathrm{Z}$ is positive in the downstream direction. Similarly, data near the inner and outer front pole covers are normalized so that $\mathrm{R}=0$ and $\mathrm{R}=1$ correspond to the inner and outer radial edges, respectively, of the region of interest.

\section{A. Thruster and Test Matrix}

All data presented in this work were collected with the HERMeS TDU1. The HERMeS TDU was designed to be a $12.5 \mathrm{~kW}, 3000 \mathrm{~s}$, magnetically-shielded Hall thruster. The thruster had been operated over discharge voltages ranging from 300 to $800 \mathrm{~V}$, corresponding to a specific impulse range of 2000 to $3000 \mathrm{~s}$ at full power. The thruster had also been throttled over discharge powers ranging from 0.6 to 12.5 $\mathrm{kW} .{ }^{9}$ The cathode mass flow rate was maintained at $7 \%$ of the anode mass flow rate.

Thruster magnet coils were energized so that the magnetic shielding topology was always maintained. The only degree of freedom in the magnetic field setting was the strength of the magnetic field. Peak radial magnetic field strength along the discharge channel centerline was chosen as the reference when referring to the strength of the magnetic field. A single magnetic field strength value was chosen as the nominal value for all operating conditions. This value was set to provide the highest thruster efficiency possible while maintaining margin against oscillation mode transitions. Figure 2 shows a picture of the NASA HERMeS TDU1 on the LIF test stand.

The specifications for the TDUs included seven Reference Firing Conditions (RFCs), which were throttle points that would be used in all TDU testing. Though the full operational range of the TDUs extends well beyond the RFCs, testing was constrained to the RFCs to limit testing cost. Table 1 lists the RFCs. The testing described in this paper focused on four of the RFCs, which are marked with asterisks.

For the testing described in this paper, the thruster body was isolated from the test stand and connected to the cathode. Prior testing had determined that this cathode-tied configuration was associated with low pole cover erosion and can be readily implemented in flight. ${ }^{15,17}$ 
During testing, the thruster was considered to be ready for data acquisition when the rate of drift in the discharge current became less than $0.5 \%$ per hour. Typical drift in discharge current was much less than this after half hour of operation at a new condition when changing operating conditions.

Thruster telemetry collected during testing showed that the HERMeS TDU1 was operating the same way as prior TDU1 testing in Vacuum Facility $6^{22}$.

\section{B. Test Facility}

Testing was performed in Vacuum Facility 6 at NASA GRC. This cylindrical facility is $7.6 \mathrm{~m}$ in diameter, 21.3 $\mathrm{m}$ long, and was evacuated with a set of cryo-pumps. The thruster was mounted on a test stand that can be moved horizontally with two cross-mounted motion stages. Figure 2 shows the thruster mounted on the test stand. Also in the figure are the reference target used for laser alignment, the collection optics, and the motion stages that move the test stand.

To accommodate the movement of the thruster while supplying high-purity propellant to the thruster, a new propellant delivery approach was developed. Key positions along stainless steel tubing were bent into coils that formed joints. Each joint provided enough flexibility to the tubing to allow movement without causing plastic deformation. The tubing was then wrapped with heat tape for bakeout to ensure high-purity propellant delivery. Figure 3 shows the coiled tubing wrapped in heat tapes.

Background pressure near the thruster was monitored with two ion gauges, which were calibrated on xenon against a spinning rotor gauge. Gauge readings were corrected for temperature and direction relative to background flux via methods described in Yim and Burt. ${ }^{24}$ Uncertainty in the calculated pressure was dominated by electrical and

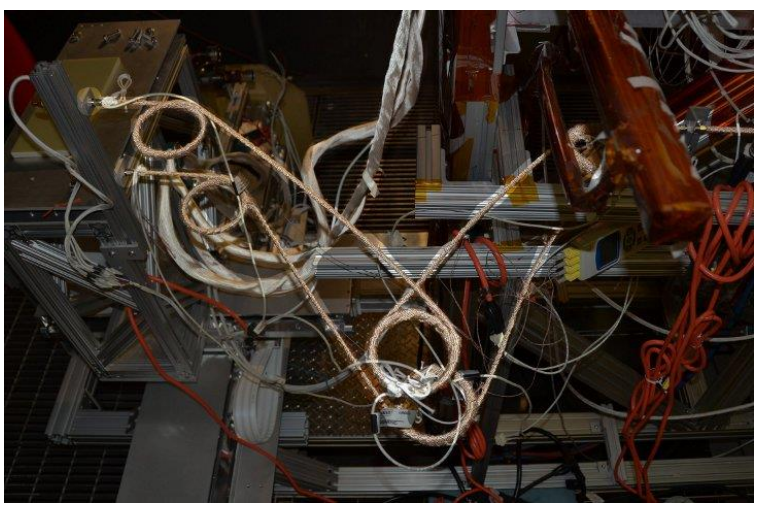

Figure 3. The propellant line coiled tubing wrapped in heat tapes for bakeout. electronic noise, which was estimated by the manufacturer to be $\pm 6 \%$ of the reading. The background pressure near the thruster for the testing described in this paper was $1.2 \times 10^{-5}$ Torr.

Research-grade xenon propellant was supplied via commercially available mass flow controllers to the thruster and cathode. These mass flow controllers were calibrated using research-grade xenon prior to testing. Typical uncertainty of measurement was $\pm 1 \%$ of reading.

Electrical power was supplied to the thruster with commercially available power supplies. Separate power supplies supported the main discharge, cathode heater, keeper, inner magnet, and outer magnet. An electrical filter was placed between the thruster and the discharge power supply. All power supplies and the filter were located outside of the vacuum facility.

\section{Diagnostics}

The LIF velocimetry scheme used in the LIF functional checkout test excites the XEII $834.953 \mathrm{~nm}$ (vac) transition and collects fluorescence from the $542.066 \mathrm{~nm}$ (vac) transition. This singly-charged xenon ion transition has an unusually narrow hyperfine structure that cannot be easily resolved even when probed with special techniques. ${ }^{25}$ At the same time, the narrowness of the hyperfine structure means that associated broadening in the lineshape for data obtained in the discharge channel of a Hall thruster is at most $4-5 \% .{ }^{25}$ Figure 4 shows a diagram of the LIF scheme used. The prior study ${ }^{25}$ did not include regions near the pole covers of the Hall thruster so further analysis will be performed in the future to determine whether corrections need to be performed.

Figure 5 shows the equipment used to inject laser light into the vacuum facility. The laser was a taper-amplified diode laser that output up to $500 \mathrm{~mW}$ at $835 \mathrm{~nm}$. Wavelength was monitored via a Fizeau-type wavemeter and an optogalvanic cell. The laser beam entering the optogalvanic cell was mechanically chopped at $\sim 1.6 \mathrm{kHz}$. The laser beam was also monitored with photodiode to track the variation in laser power. The laser beam was split into three branches. Each branch passed through a separate electro-optical modulator and was collimated into optical fibers. A modulation frequency study showed that the signal-to-noise ratio (SNR) optimized at around $300 \mathrm{kHz}$ to $350 \mathrm{kHz}$ in modulation frequency.

Figure 6 shows a diagram of the optics setup inside the vacuum facility. Three sets of injection optics where deployed. The optical fibers from the air-side setup were sent to each of the three sets of injection optics. Each set of injection optics had two motors that allowed remote control of the tilt and pan. The optics on axis 1, the axial axis, was protected from most of the heat of the plasma by a shield. Additionally, the support structure for the axis 1

4

American Institute of Aeronautics and Astronautics 
optics was equipped with an internal cooling line connected to an external chiller. The thruster was mounted to the motion stages that provide radial and axial movements. A reference target was mounted at a known distance from the thruster in the same plane as the three injected laser beams. Two cameras monitored the positions of the injected laser beams relative to the reference target. The collection optics were mounted $70^{\circ}$ out of the injection plane. An optical fiber carried fluorescence signal from the collection optics out of the vacuum facility. The spatial resolution of the measurements was limited by the beam waist of the injection beams and the viewing cone of the collection optics to approximately $1 \mathrm{~mm}$ in size.

Figure 7 shows a picture of the equipment that processed the fluorescence signal. The light from the collection optical fiber was collimated into a monochromator and sent to a photomultiplier. The photomultiplier current was converted to voltage via a high-speed trans-impedance amplifier. The output voltage signal was coupled into three digital lock-in amplifiers. A fourth digital lock-in amplifier measured the signal from the optogalvanic cell. A computer controlled the movement of various stages, swept the laser wavelength, and recorded the various output signals. Lock-in amplifier time constant varied from $300 \mathrm{~ms}$ to $1 \mathrm{~s}$.

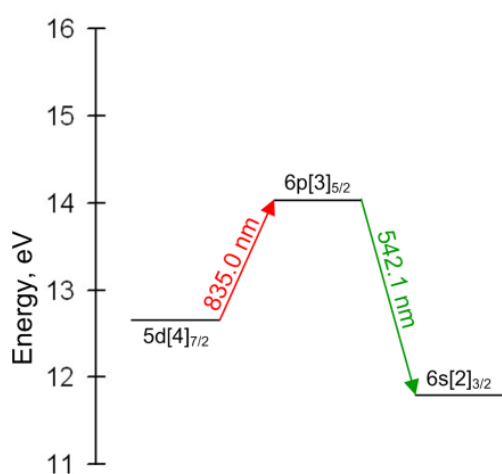

Figure 4. Transition diagram for Xe II LIF at $834.953 \mathrm{~nm}$ (vac).

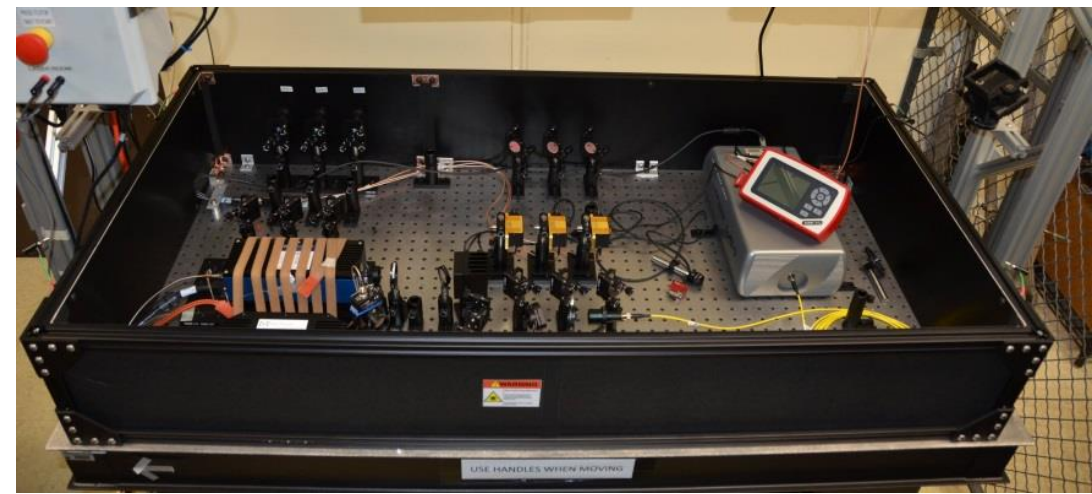

Figure 5. Air-side laser injection setup.

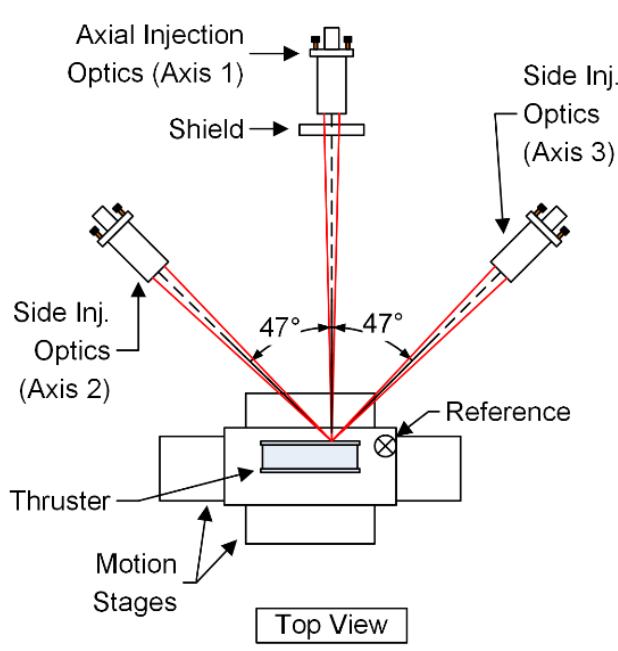

(a)

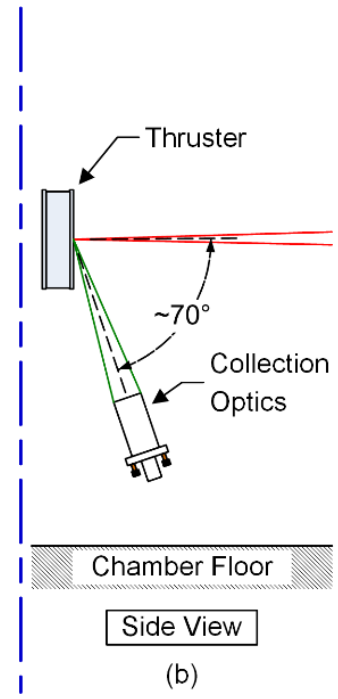

(b)

Figure 6. Vacuum-side optical setup.

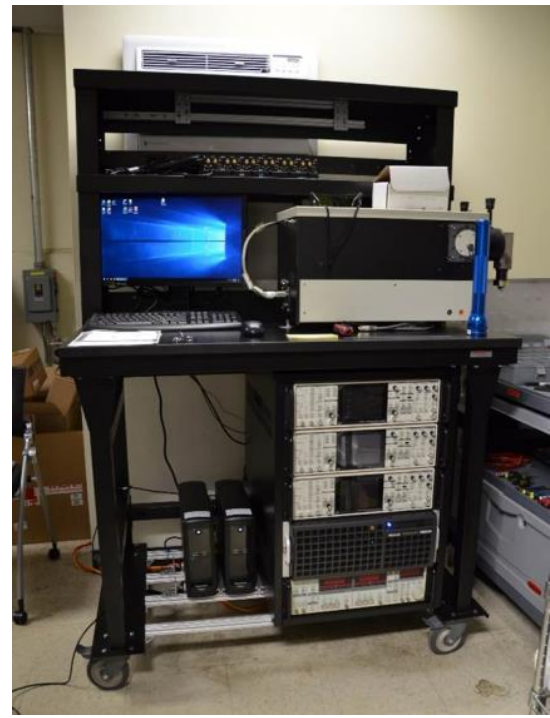

Figure 7. Fluorescence signal processing equipment.

\section{In-situ Optics Alignment}

Due to the small size of the interrogation zone relative to the length scale of the rest of the vacuum facility, shifts in laser alignment over the course of the experiment can easily take the injected beams and the collection optics out of alignment if not corrected for. These shifts in laser alignment were driven by the length of various support structure holding the optics and the amount of heating the structures experienced during thruster operation. A system 


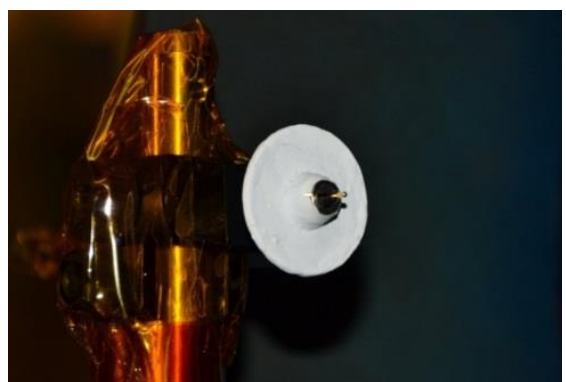

Figure 8. Reference target.

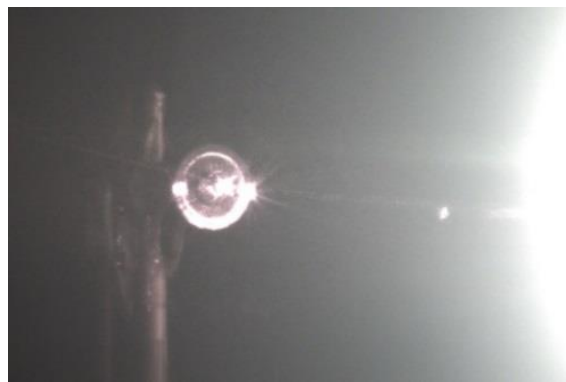

Figure 9. Laser being aligned while thruster operated

for in-situ alignment of the vacuum optics was developed based on a prior test setup ${ }^{26}$ in anticipation of alignment issues.

The new LIF system made two key improvements over the previous approach. Previously, laser light from the injection optics were focused on to a reference pin and scattered light collected by the collection optics. This setup was extremely sensitive to the relative position of the laser beam, pin, and the collection optics making the pin a very effective alignment tool. However, if the laser beam ever drifted too far out of position (more than $1 \mathrm{~mm}$ ), recovering the alignment without venting was often difficult. The new LIF system incorporates a washer coated with white ceramic paste and two in-vacuum cameras to help identify the relative position of the laser beams with respect to the reference pin. Furthermore, laser light striking the pin produces unique scattering patterns that were easy to recognize and provided an additional feedback beyond the scatter light collected by the collection optics for fine alignment. Figure 8 shows a close-up image of the reference target. Figure 9 shows an image captured by an invacuum camera during an alignment check while the thruster was operating. The in-vacuum cameras had their IRcut filters removed.

\section{Data Analysis}

\section{A. Analysis Method}

A saturation study was performed at the beginning of the test campaign to pick out injection laser power that balances saturation broadening and SNR (i.e. high laser intensity leads to higher SNR but also more saturation broadening). The amount of broadening was kept to below $10 \%$. A more indepth analysis will be performed later to determine the amount of broadening for each scan. For the data presented in this paper, the amount of saturation broadening is no more than $10 \%$.

No attempt was made to remove the hyperfine structure broadening as they contribute no more than $5 \%$ broadening. ${ }^{25}$ Since lineshape broadening add as square root of the sum of squares of individual broadening terms, hyperfine structure broadening may be overshadowed by saturation broadening. Treatment of hyperfine structure broadening is saved for when in-depth saturation broadening analysis are performed. On the other hand, Zeeman Effect can greatly broaden and distort the lineshape and will be analyzed in-depth in a future work.

The first step in the data analysis was to convert readings from the wavemeter and optogalvanic cell into frequency shift from the stationary transition frequency. This frequency shift was sometimes referred to as the detuning. The

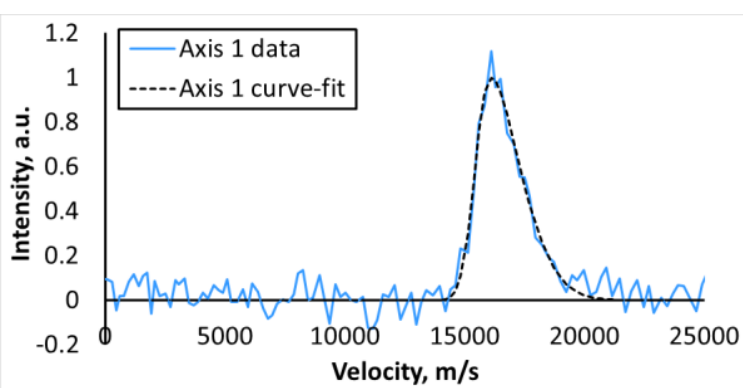

Figure 10. An example of skew-normal curve-fit.

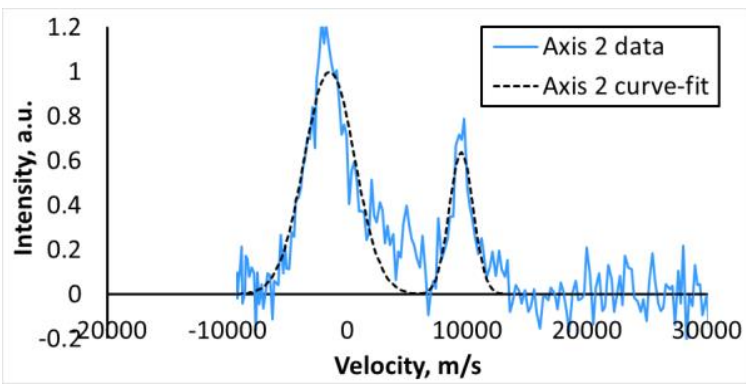

Figure 11. An example of twin Gaussian curve-fit. detuning was then converted into a velocity scale.

The intensity data was corrected for changes in laser power by using a combination of photodiode and thermopile measurements. First, the laser power as measured by the thermopile and the photodiode were collected in a controlled study. Then, the photodiode measure during data acquisition was corrected by the results of the 
controlled study to provide an accurate measurement of the laser power. This correction removed artificial features that may have been created in the intensity data due to variations in laser power as the wavelength varied.

Next, curve-fits were performed on the intensity versus the velocity. Three different types of curve-fits were used including skew-normal, Gaussian, and twin Gaussian functions. Figure 10 shows an example of skew-normal curve-fit. Figure 11 shows an example of twin Gaussian curve-fit. Once the curve-fits were performed, averaged velocities and full-width-at-half-maximum (FWHM) velocities were calculated. Twin Gaussian fits were used for lineshapes that displayed Zeeman splitting and spatial oscillation. These scenarios were identified based on interrogation location as they tend to show up in very specific regions. A single averaged velocity was generated for these two types of lineshapes. Additionally, twin Gaussian fits were used for lineshapes that contain both the high energy main beam and the low energy charge-exchange (CEX) population. Later plots will show where CEX populations tended to be measurable. The results from the twin Gaussian fits for lineshapes with two energy population allow the averaged velocity of each population to be calculated.

\section{B. Uncertainty Analysis}

The uncertainty in position was dominated by the size of the interrogation zone and the drift in alignment of the optics. The alignment procedure used in this LIF test rejected data where alignment drifted by more than $0.5 \mathrm{~mm}$ from the reference.

The SNR was an important metric in assessing uncertainty in the data. The SNR was defined as the ratio of the peak signal divided by the standard deviation of the noise. Typically, any trace with an SNR of 3 or less was considered to be statistically insignificant. At this value of SNR, any peak present was barely detectable against the noise. Since three injection laser axes were used, if the SNR was low on one axis, a velocity vector could still be calculated from the remaining two axes. On a number of occasions, this redundancy allowed a more complete set of data to be collected. Mathematics associated with calculating axial and radial components of the velocity from an arbitrary set of laser injection axes are shown in the appendix. Where reliable data was available from all three axes, calculations of the axial velocity were performed using different combination of the injection data to help assess the uncertainties in the calculated velocities. A direct assessment of more than 300 data points across various operating conditions showed that the uncertainties were typically within $\pm 100 \mathrm{~m} / \mathrm{s}$ but could rise to as high as $\pm 600 \mathrm{~m} / \mathrm{s}$ for scans with low SNR (SNR just high enough to make out the presence of the peak). The uncertainty from the wavemeter and optogalvanic cell combination was $\pm 50 \mathrm{~m} / \mathrm{s}$ and is much lower than the uncertainty from the noise. Uncertainty associated with scanning resolution of the laser was calculated to limit the absolute accuracy of the mean velocity to approximately $\pm 100 \mathrm{~m} / \mathrm{s}$, which is in good agreement with the direct assessment of the data.

\section{Results}

\section{A. Ion Velocity along the Discharge Channel Centerline}

To successfully validate thruster plasma models, the most important thruster locations to study are in the discharge channel, particularly around the acceleration region. The most basic data sets that LIF can provide are ion velocities along the discharge channel centerline and in the discharge channel, which are the focus of the following two-subsections.

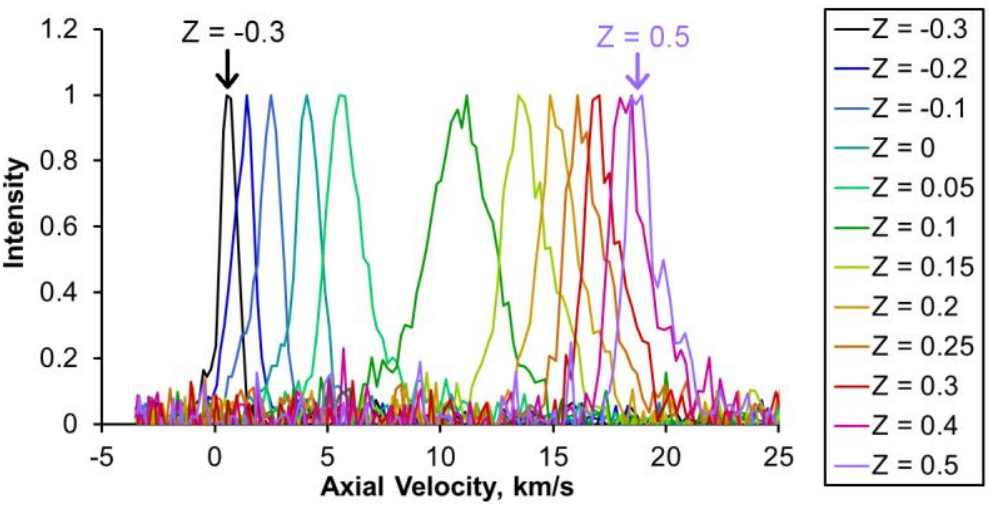

Figure 12. Lineshapes at select locations along the discharge channel centerline for the $300 \mathrm{~V}, 6.3 \mathrm{~kW}$ condition.

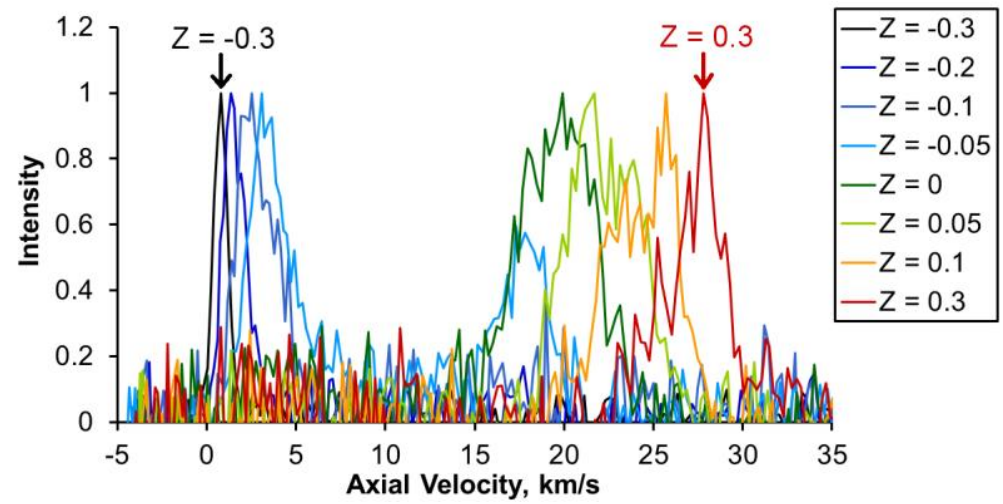

Figure 13. Lineshapes at select locations along the discharge channel centerline for the $600 \mathrm{~V}, 12.5 \mathrm{~kW}$ condition.

American Institute of Aeronautics and Astronautics 
Figure 12 shows the axial velocity distributions found along the discharge channel centerline for the $300 \mathrm{~V}, 6.3$ $\mathrm{kW}$ condition. Figure 13 shows the same for the $600 \mathrm{~V}, 12.5 \mathrm{~kW}$ condition. Data in these figures were collected from axis 1 .

From Figure 12, one could see that the ion VDF broadened as the ions accelerated before narrowing again. The broadening of ion VDFs inside the acceleration zone had been tied to axial movement in the acceleration profile associated with breathing mode oscillations. ${ }^{26,27}$

From Figure 13, one could see a different sort of VDF broadening that was likely associated with a sinusoidal oscillation unique to magnetically-shielded Hall thruster. More precisely, this oscillation mode has only been observed to dominate for magnetically-shielded Hall thrusters operating at high discharge voltage $(500+\mathrm{V}) .{ }^{10}$ As the ions were accelerated, their VDFs began to exhibit two-peak structures that were highly reminiscent of probability density function of harmonic oscillators (see Figure 2 of Huang, et al ${ }^{26}$ for an example of how harmonic oscillation give rise to probability density function with two peaks). Notably, the largest separation between the two peaks was associated with the highest change in velocity. This behavior agrees well with the idea that the acceleration profile was moving axially as a whole. Looking at it from a different perspective, if the acceleration profile underwent the same amount of axial movement everywhere, the location with the highest velocity gradient would also display the highest variation in velocity.

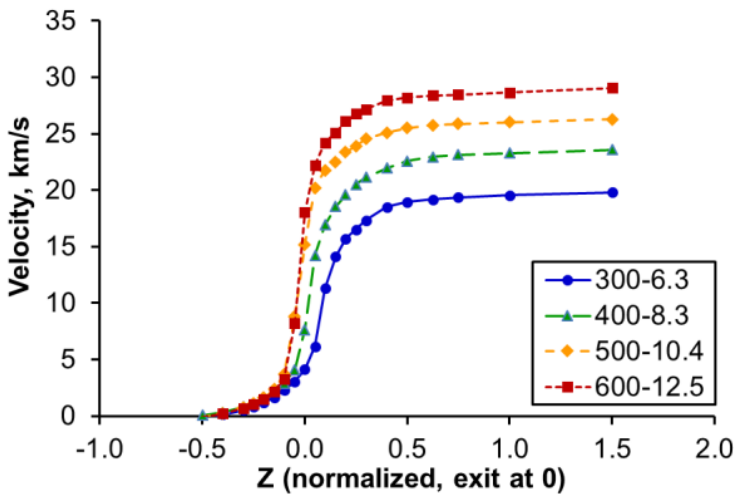

Figure 14. Averaged axial velocity along the discharge channel centerline of the TDU1.

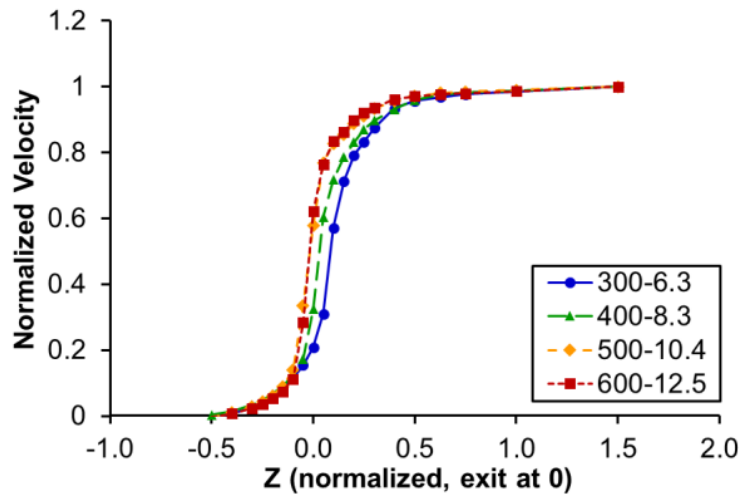

Figure 15. Normalized averaged axial velocity along discharge channel centerline of the TDU1.

Figure 14 shows the averaged axial velocity as a function of position for the four RFCs included in this paper. This data is in good general agreement with another LIF study performed on TDU2 by Chaplin, et al. ${ }^{18}$. The TDU2 study was performed in the Owens chamber at JPL. Ion gauges were installed at matching distances and orientations for the LIF studies conducted at JPL and GRC and measured background pressures were within 10\% of each other.

Figure 15 shows the averaged axial velocity normalized by the maximum averaged velocity for each condition. Notably, the acceleration profile was sharper and more upstream for the $500 \mathrm{~V}, 10.4 \mathrm{~kW}$ and $600 \mathrm{~V}, 12.5 \mathrm{~kW}$ operating conditions than for the $400 \mathrm{~V}, 8.3 \mathrm{~kW}$ condition, which is more upstream than for the $300 \mathrm{~V}, 6.3 \mathrm{~kW}$ condition. The sharpest rise in velocity for the $600 \mathrm{~V}, 12.5 \mathrm{~kW}$ data corresponded to the two-peak VDFs shown in Figure 13.

\section{B. Ion Velocity near the Discharge Channel}

In and near the discharge channel, data were obtained over a two-dimensional domain. Data on axes 2 and 3 generally had higher SNR than data on axis 1 and was used to generate the vector plots. Lower SNR on axis 1 was due in part to the fact that the VDFs tended to be more spread out in the direction of travel so a mostly axial ion population tended to have a broader VDF with a lower peak height along the axial direction than along any other directions. Recall that SNR was defined as peak height divided by standard deviation of the noise. Low energy populations were identified in scans near the radial outer edge of the interrogated domain. Based on the location, direction, and energy, these low energy populations are most likely CEX ions.

Figure 16 shows the vector plot for ion velocity data obtained near the discharge channel for the $300 \mathrm{~V}, 6.3 \mathrm{~kW}$ condition. As seen in the figure, the plume for this operating condition was characterized by a relatively high divergence. The presence of the beam energy peaks tended to dominate over low energy CEX peaks. Even so, close examination of scans along the radial outer edge of the interrogation domain revealed the presence of CEX ions. Figure 17 shows an example of one such scan. The CEX population showed up as low and wide VDFs with averaged velocities that are small in comparison to the main beam population. 
Figure 18 shows a plot of ion energy per charge versus polar angle for the $300 \mathrm{~V}, 6.3 \mathrm{~kW}$ condition. ${ }^{17}$ This data was obtained using a far-field retarding potential analyzer (RPA). Each vertical slice in Figure 18 represents one RPA trace. Normalization was performed against the peak signal for each trace so that dark red represents the energy of the dominant peak at each polar angle. This figure confirms that the high energy ions were dominant over a large range of angles $\left( \pm 80^{\circ}\right)$. At the same time, low energy CEX ions were still detectable at very high polar angles just as they were detectable within the LIF scans when closely examined.

Figure 16 also show most of the only near-chamfer data that were collected during testing. In general, SNR was very low near the chamfer and the ions present were generally parallel to the chamfer and at very low energies. This discovery is in agreement with the fact that HERMeS was designed from scratch to be magnetically shielded. For a magnetically-shielded thruster, plasma near the chamfers are characterized by low density and low ion energy.

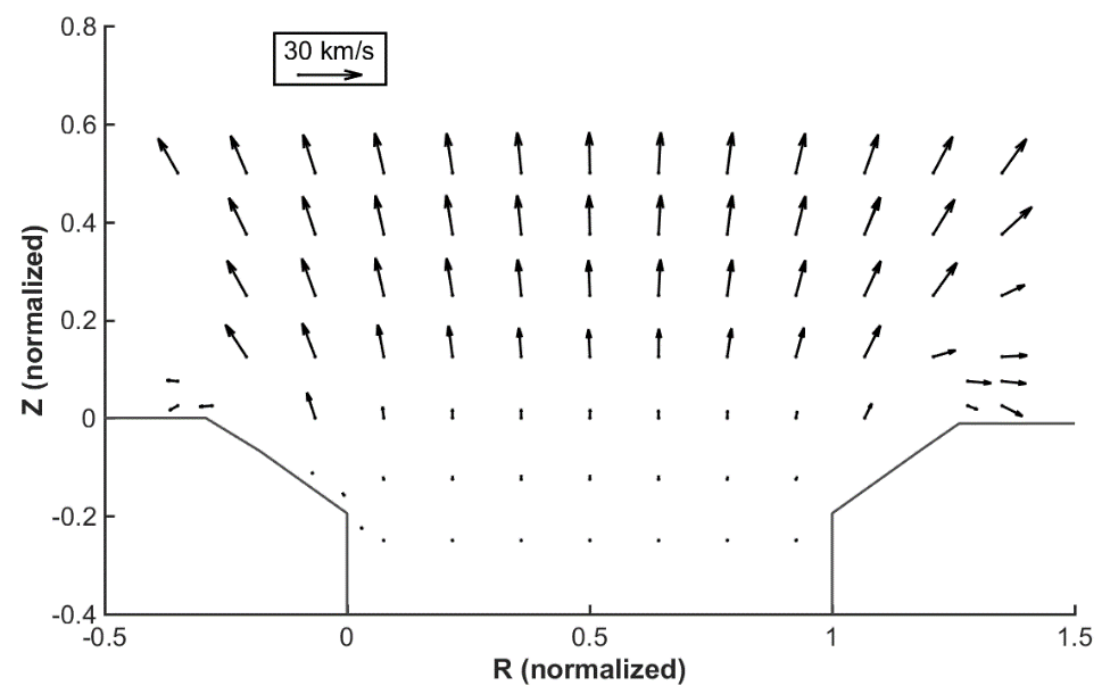

Figure 16. Averaged velocity vector in and near the discharge channel for the $300 \mathrm{~V}, 6.3 \mathrm{~kW}$ condition.

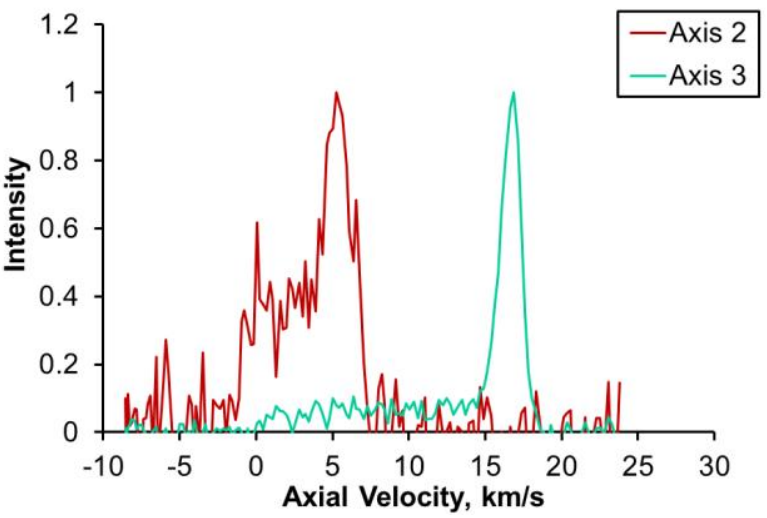

Figure 17. Axis 2 and 3 VDFs at $R=1.07$ and $Z=$ 0.25 for the $300 \mathrm{~V}, 6.3 \mathrm{~kW}$ condition.

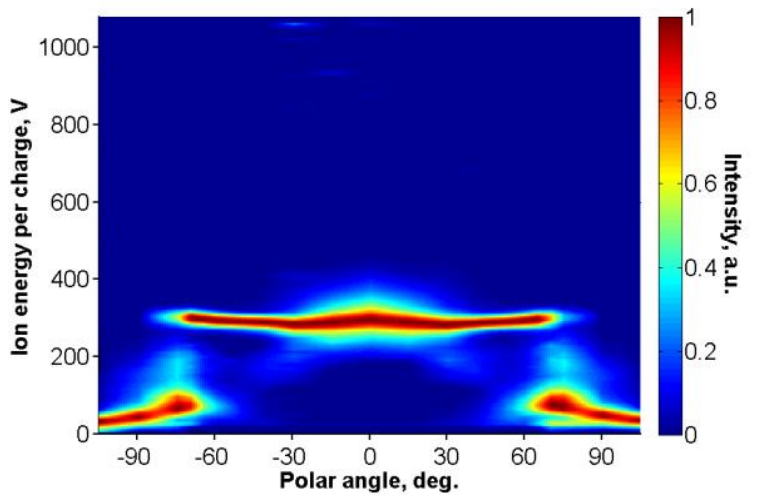

Figure 18. Ion energy per charge versus polar angle for the $300 \mathrm{~V}, 6.3 \mathrm{~kW}$ condition. ${ }^{17}$

Figure 19 shows the vector plot for ion velocity data obtained near the discharge channel for the $600 \mathrm{~V}, 12.5 \mathrm{~kW}$ condition. As seen in the figure, the plume for this operating condition was characterized by a relatively low divergence. Low energy CEX population was readily discernible in LIF traces taken along the radially outer portion of the interrogation domain. These low energy populations are denoted as blue arrows in Figure 19 (as opposed to black arrows for the main beam population). This low energy population was not easily discernible for the $300 \mathrm{~V}$, $6.25 \mathrm{~kW}$ operating condition and was not plotted in Figure 16. Figure 20 shows raw lineshapes recorded at one such location for the $600 \mathrm{~V}, 12.5 \mathrm{~kW}$ condition. The low energy population was clearly discernible and of competing magnitude as the high energy population. Furthermore, in the part of the interrogation domain axially close to the 
exit plane and radially towards the outer front pole cover, no high energy populations could be detected but low energy populations were present.

Figure 21 shows a plot of ion energy per charge versus polar angle for the $600 \mathrm{~V}, 12.5 \mathrm{~kW}$ condition. ${ }^{17}$ This data was obtained in the same way as the data shown in Figure 18. This far-field RPA data is in excellent agreement with the near-field LIF data. By tracing the black and blue arrows from Figure 19 out into the far-field one can see that most of the higher energy beam ions ended up somewhere within $\pm 45^{\circ}$ of the thruster firing axis while the higherpolar-angle regions were dominated by low energy CEX ions. The average energy of the CEX ions detected in the LIF scans ranged from 60 to $90 \mathrm{eV}$ with high tails that reached in excess of $200 \mathrm{eV}$. This trend matched the RPA traces in the far-field at high polar angles.

Comparing Figure 16 and Figure 19, one can see that the ion beam was noticeable more collimated for the 600 $\mathrm{V}, 12.5 \mathrm{~kW}$ condition than for the $300 \mathrm{~V}, 6.3 \mathrm{~kW}$ condition. This behavior is in agreement with past Faraday probe measurements on the TDUs. ${ }^{17}$ Notably, the ions have picked up a fair bit of energy by the time they reached the exit plane $(\mathrm{Z}=0)$ for the $600 \mathrm{~V}, 12.5 \mathrm{~kW}$ condition but not for the $300 \mathrm{~V}, 6.3 \mathrm{~kW}$ condition, as was shown in Figure 14.

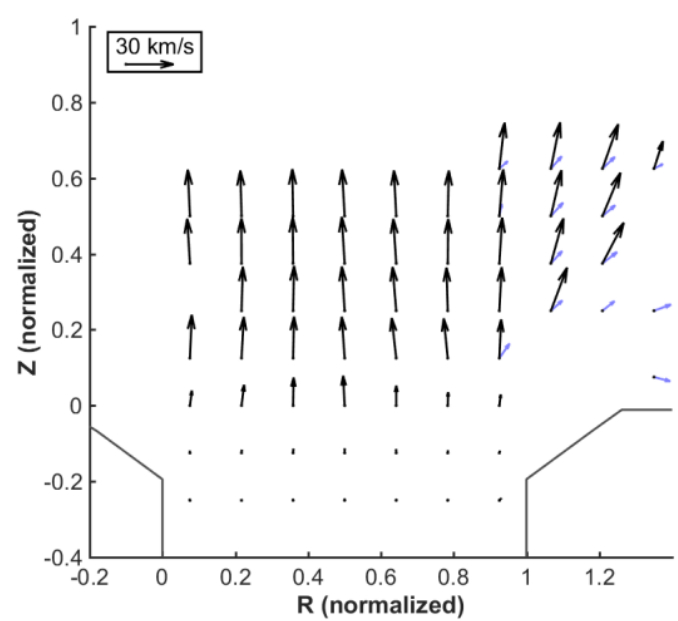

Figure 19. Averaged velocity vector in and near the discharge channel for the $600 \mathrm{~V}, 12.5 \mathrm{~kW}$ condition.

The presence of CEX ions was not a surprise as the plasma density in the near-field was more than high enough to generate these ions. What was unexpected was the energies that some of these CEX ions reached $(200+\mathrm{eV})$. Note that the possibility also exists that some of the low energy population were ions that were ionized well downstream of the main ionization zone. However, in this region just downstream of the bulk of the Hall current, charge-exchange collision frequencies are much higher than ionization collision frequencies.

An alternate hypothesis to the charge-exchange ion idea is the possibility that the low energy population was a result of plasma oscillations (like the breathing mode for $300 \mathrm{~V}$ operation and the harmonic oscillator mode for $600 \mathrm{~V}$ operation ${ }^{10}$ ). A close inspection of the axis 2 VDF in Figure 20 revealed that this VDF looked very similar to the $Z=$ -0.05 VDF in Figure 13. There is a possibility that, like the $\mathrm{Z}=-0.05 \mathrm{VDF}$ on the discharge channel centerline, the VDFs along the radially outer region of the discharge channel that displayed two peaks were actually displaying the time-averaged result of oscillating VDFs. The counter argument against this hypothesis include that there is no clear mechanism for discharge channel oscillations to generate this level of ion energy variation so far outside of the discharge channel. Time-resolved LIF could be used to determine which of the two hypotheses is correct.

\section{Ion Velocity near the Front Pole Covers}

American Institute of Aeronautics and Astronautics 
One of the most important reason for performing the LIF studies presented in this paper was to try to establish ground truth on the physics driving erosion of the HERMeS TDU pole covers. Having removed chamfer erosion as a life limiting mechanism by implementing magnetic shielding, pole cover erosion is considered the next potential life limiting mechanism with respect to thruster wear. In prior work on the H6MS, Jorns, et al., discovered that the regions just downstream of the pole covers were dominated by low energy CEX ions. ${ }^{28}$ Erosion of the pole covers by CEX ions were insufficient to explain measured erosion rates on the same thruster. ${ }^{29}$ However, they speculated on the possible existence of a small population of high energy (about half of beam energy) predicted by simulation that could make up for the discrepancy observed. Said population would have been too small to show up in that LIF study. ${ }^{28}$ Although HERMeS TDU is not the same as the H6MS, the two thrusters are both magnetically shielded and the H6MS studies were a prelude to the kinds of issues we would have to tackle on the HERMeS TDU. A portion of the LIF test was devoted to obtaining VDFs of the ions bombarding the pole covers.

Figures 22, 24, 26, and 28 show the averaged ion velocity vectors near the inner front pole cover (IFPC) for the $300-6.3,400-8.3,500-10.4$, and 600-12.5 operating conditions, respectively. Figures 23 , 25, and 27 show the same for the outer front pole cover (OFPC) for the 300-6.3, 400-8.3, and 500-10.4 operating condition, respectively. SNR for data obtained near the OFPC decreased with increasing discharge voltage to the point where no useable data was obtained when the thruster operated at $600 \mathrm{~V}, 12.5 \mathrm{~kW}$.

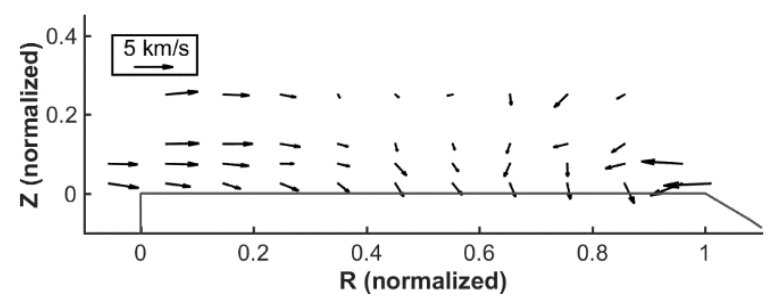

Figure 22. Averaged velocity vector near the inner front pole cover for the $300 \mathrm{~V}, 6.3 \mathrm{~kW}$ condition.

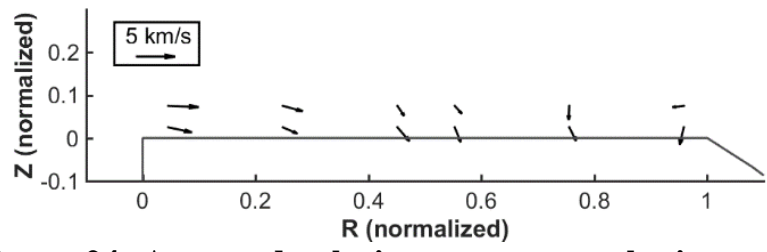

Figure 24. Averaged velocity vector near the inner front pole cover for the $400 \mathrm{~V}, 8.3 \mathrm{~kW}$ condition.

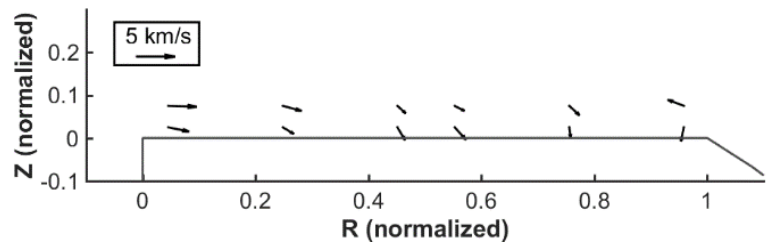

Figure 26. Averaged velocity vector near the inner fron pole cover for the $500 \mathrm{~V}, 10.4 \mathrm{~kW}$ condition.

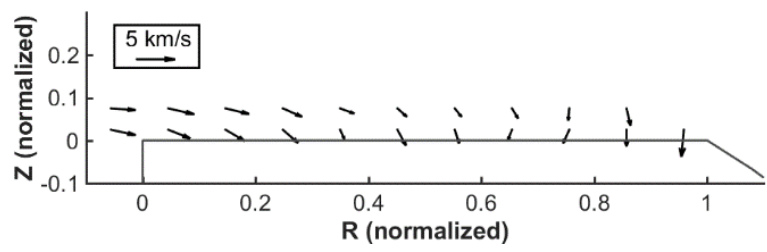

Figure 28. Averaged velocity vector near the inner front pole cover for the $600 \mathrm{~V}, 12.5 \mathrm{~kW}$ condition.

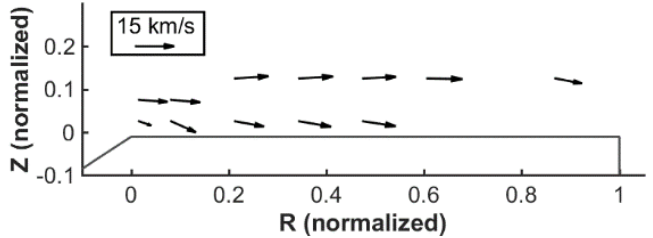

Figure 23. Averaged velocity vector near the outer front pole cover for the $300 \mathrm{~V}, 6.3 \mathrm{~kW}$ condition.

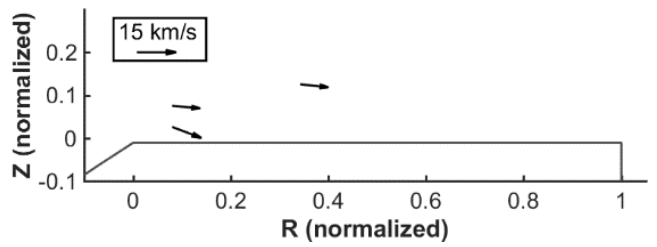

Figure 25. Averaged velocity vector near the outer front pole cover for the $400 \mathrm{~V}, 8.3 \mathrm{~kW}$ condition

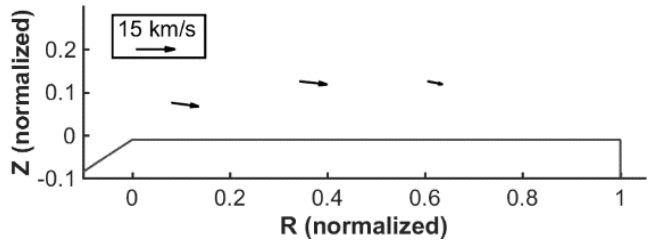

Figure 27. Averaged velocity vector near the outer front pole cover for the $500 \mathrm{~V}, 10.4 \mathrm{~kW}$ condition. 
The FWHM energy will be used to characterize the spread in ion energy. The FWHM energy is the width of the energy distribution function as derived from the VDF measured at half of maximum intensity. This parameter is for the ion energy distribution function what the FWHM velocity is for the VDF.

From the figures showing the IFPC data, one can see that the local ion trajectories point into the IFPC. The average energy of ions bombarding the IFPC was around $10 \mathrm{eV}$ (note the different reference vectors used for the different vector plots). These ions also had an apparent spread in energy with FWHM energies of 19 to $74 \mathrm{eV}$ (as measured along axes 2 and 3). Note that these VDFs were typically not isotropic and not thermalized so the term temperature is not applicable. The LIF scans in this region are known to be affected by Zeeman Effect so some of the broadness in the IFPC VDFs is artificial. The Zeeman Effect will be corrected for in a future study.

Data from near the OFPC show a different scenario than data from the IFPC. In general, ions near the OFPC have shallower bombardment angles than ions near the IFPC. Although the ions present were still low in energy relative to the main beam, their energies were quite a bit higher than their IFPC counterpart. Average ion energy near the OFPC reached 75 to $119 \mathrm{eV}$. Furthermore, the width of the VDFs were found to be very large. The associated FWHM energy ranged from 33 to $155 \mathrm{eV}$. Table 2 provides a preliminary summary of the energy characteristics of the ions bombarding the pole covers. Further analysis is needed.

Table 2. Preliminary summary of the energy characteristics of the ions bombarding the pole covers.

\begin{tabular}{ccccc}
\hline $\begin{array}{c}\text { Operating } \\
\text { condition }\end{array}$ & $\begin{array}{c}\text { Average ion } \\
\text { energy, IFPC, } \text { eV }\end{array}$ & $\begin{array}{c}\text { FWHM energy, } \\
\text { IFPC, } \mathrm{eV}^{*}\end{array}$ & $\begin{array}{c}\text { Average ion } \\
\text { energy, OFPC, } \text { eV }\end{array}$ & $\begin{array}{c}\text { FWHM energy, } \\
\text { OFPC, eV }\end{array}$ \\
\hline $\mathbf{3 0 0 - 6 . 3}$ & $\mathbf{0}$ to 20 & 25 to 72 & $\mathbf{8 1}$ to 119 & 33 to 91 \\
$\mathbf{4 0 0 - 8 . 3}$ & $\mathbf{3}$ to 7 & 19 to 74 & 77 to 99 & 97 to 145 \\
$\mathbf{5 0 0 - 1 0 . 4}$ & 2 to 5 & 26 to 46 & 75 to 77 & 102 to 155 \\
$\mathbf{6 0 0 - 1 2 . 5}$ & $\mathbf{2}$ to 15 & 20 to 48 & Low signal & \\
\hline
\end{tabular}

*VDFs near IFPC were artificially broadened by Zeeman Effect.

\section{Conclusions}

NASA GRC has developed a new LIF diagnostic system for use with high-power electric propulsion devices. The use of this LIF system was successfully demonstrated in a test in VF6 with the HERMeS TDU. Initial test results at four conditions spanning 300 to $600 \mathrm{~V}$ discharge voltage were in excellent agreement with another TDU test in JPL's Owens chamber when the two tests were conducted at the same background pressure. ${ }^{18}$

An extended spatial map of the plasma plume demonstrated that the new system was able to detect low energy ions that may consist mostly of charge-exchange ions. These low energy ions were found to originate from axial locations downstream of the main ionization zone and they travel at a high angle relative to the firing axis away from the high energy beam ions. An examination of far-field RPA data showed good correlation between the trajectories and energies of the low and high energy populations found in the near-field and their angular positions in the far-field.

A preliminary analysis of the LIF data obtained from near the two pole covers revealed that the local ion populations have bulk velocity vectors pointed towards the pole covers. Specifically, ions near the IFPC tended to have low averaged energies while the ions near the OFPC tended to have high averaged energies. Both populations of ions exhibited large spread in energies. Ions near the OFPC also tended to bombard the OFPC at a shallower angle than their IFPC counterparts. Further analysis need to be performed to resolve possible broadening by Zeeman Effect as well determine how much of the pole cover erosion can be accounted for with only ion populations detected by LIF. 


\section{Appendix}

Equations for calculating the averaged axial and radial velocities for the setup illustrated in Figure 6 will be derived in this appendix. When planning an LIF setup that uses only two injection axes, one should ideally be orthogonal to the other to minimize uncertainty associated with velocity vector projection. However, a realistic setup cannot always achieve perfect orthogonality. The equations will be derived with arbitrary angles between the axial axis and the injection axes. Figure 29 shows a diagram of the associated setup. Let $\theta_{2}$ be the angle between axes 2 and the axial axis, and let $\theta_{3}$ be the same between axis 3 and the axial axis. $V_{2}$ and $V_{3}$, the averaged velocities along axes 2 and 3, respectively, can be calculated by geometry from the $\mathrm{V}_{\mathrm{z}}$, the averaged axial velocity, and $\mathrm{V}_{\mathrm{r}}$, the averaged radial velocity as follows in Eqs. (1) and (2).

$$
\begin{aligned}
& \mathrm{V}_{2}=\mathrm{V}_{\mathrm{z}} \cos \theta_{2}-\mathrm{V}_{\mathrm{r}} \sin \theta_{2} \\
& \mathrm{~V}_{3}=\mathrm{V}_{\mathrm{z}} \cos \theta_{3}+\mathrm{V}_{\mathrm{r}} \sin \theta_{3}
\end{aligned}
$$

Solving for $\mathrm{V}_{\mathrm{z}}$ and $\mathrm{V}_{\mathrm{r}}$ yields Eqs. (3) and (4).

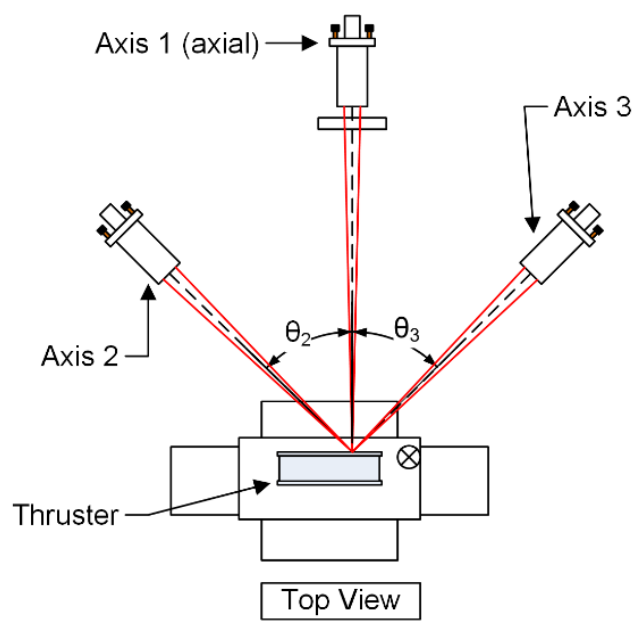

Figure 29. LIF setup with arbitrary axes 2 and 3 angles.

$$
\begin{aligned}
& \mathrm{V}_{\mathrm{z}}=\frac{\mathrm{V}_{2} \sin \theta_{3}+\mathrm{V}_{3} \sin \theta_{2}}{\cos \theta_{2} \sin \theta_{3}+\cos \theta_{3} \sin \theta_{2}} \\
& \mathrm{~V}_{\mathrm{r}}=\frac{\mathrm{V}_{3} \cos \theta_{2}-\mathrm{V}_{2} \cos \theta_{3}}{\cos \theta_{2} \sin \theta_{3}+\cos \theta_{3} \sin \theta_{2}}
\end{aligned}
$$

If $\theta_{2}=\theta_{3}=\theta$, Eqs. (3) and (4) can be simplified into Eqs. (5) and (6), respectively.

$$
\begin{aligned}
& \mathrm{V}_{\mathrm{z}}=\frac{\mathrm{V}_{2}+\mathrm{V}_{3}}{2 \cos \theta} \\
& \mathrm{V}_{\mathrm{r}}=\frac{\mathrm{V}_{3}-\mathrm{V}_{2}}{2 \sin \theta}
\end{aligned}
$$

Eq.(5) was used to assess the uncertainty associated with the LIF approach described in this paper.

\section{Acknowledgments}

The authors would like to thank the Space Technology Mission Directorate through the Solar Electric Propulsion Technology Demonstration Mission Project for funding the joint NASA GRC and JPL development of the HERMeS thruster and this work. The authors would like to thank Todd Tofil for managing the electric propulsion work within the SEP Project and the thruster lead, Richard R. Hofer, for managing the thruster work. The authors would also like to thank Christopher M. Griffiths, John T. Yim, Thomas W. Haag, Timothy R. Sarver-Verhey, Jonathan A. Mackey, Lauren K. Clayman, James L. Myers, Li C. Chang, Dale A. Robinson, Maria Choi, Timothy Gray, Jason Frieman, Luis Pinero, Gabriel Benavides, Peter Peterson, George Williams, James Gilland, Scott Hall of the NASA Glenn Research Center and James E. Polk, Ioannis G. Mikellides, Alejandro Lopez Ortega, Ryan W. Conversano, Vernon H. Chaplin, Robert Lobbia of the Jet Propulsion Laboratory for work on the SEP TDM HERMeS Hall thruster. And the authors would like to thank Michael W. Swiatek, Richard G. Senyitko, Nick Lalli, Kevin L. Blake, George P. Jacynycz, Thomas A. Ralys, and Terrell J. Jensen, Michael McVetta, Luke Sorrelle, Derek Patterson, Joshua Gibson, Richard Polak, Matthew T. Daugherty, and James M. Szelagowski for assembly of the test setup and test article as well as operation of the vacuum facility.

\section{References}

${ }^{1}$ Smith, B. K., Nazario, M. L., and Cunningham, C. C., "Solar Electric Propulsion Vehicle Demonstration to Support Future Space Exploration Missions", Space Propulsion 2012, Bordeaux, France, May 7-10, 2012. 
${ }^{2}$ Congress, "National Aeronautics and Space Administration Transition Authorization Act of 2017", 2017.

${ }^{3}$ NASA HQ, "Meeting Agenda and Minutes", NASA Advisory Council Human Exploration and Operations Committee Meeting, https://www.nasa.gov/sites/default/files/atoms/files/nac heoc march 2017 public agenda revb.pdf, cited: Mar $28,2017$.

${ }^{4}$ Gerstenmaier, W., "Progress in Defining the Deep Space Gateway and Transport Plan", NASA Advisory Council Human Exploration and Operations Committee Meeting, https://www.nasa.gov/sites/default/files/atoms/files/nss chart v23.pdf, cited: Mar 28, 2017.

${ }^{5}$ Herman, D., et al., "Overview of the Development and Mission Application of the Advanced Electric Propulsion System (AEPS)", 35th International Electric Propulsion Conference, 2017-284, Atlanta, GA, Oct 8-12, 2017.

${ }^{6}$ Hofer, R. R., et al., "Development Status of the 12.5 kW Hall Effect Rocket with Magnetic Shielding (HERMeS)", 35th International Electric Propulsion Conference, 2017-231, Atlanta, GA, Oct 8-12, 2017.

${ }^{7}$ Huang, W., Yim, J. T., and Kamhawi, H., "Design and Empirical Assessment of the HERMeS Hall Thruster Propellant Manifold", 62nd Joint Army-Navy-NASA-Air Force Propulsion Meeting, JANNAF-2015-3926, Nashville, TN, Jun 1-4, 2015.

${ }^{8}$ Shastry, R., Huang, W., and Kamhawi, H., "Near-Surface Plasma Characterization of the 12.5-kW NASA TDU1 Hall Thruster", 51st AIAA/ASME/SAE/ASEE Joint Propulsion Conference, AIAA-2015-3919, doi:10.2514/6.2015-3919, Orlando, FL, Jul 27-29, 2015.

${ }^{9}$ Kamhawi, H., et al., "Performance and Facility Background Pressure Characterization Tests of NASA's 12.5-kW Hall Effect Rocket with Magnetic Shielding Thruster", 34th International Electric Propulsion Conference, 2015-007, Kobe, Japan, Jul 4-10, 2015.

${ }^{10}$ Huang, W., Kamhawi, H., and Haag, T. W., "Plasma Oscillation Characterization of NASA's HERMeS Hall Thruster via High Speed Imaging", 52nd AIAA/ASME/SAE/ASEE Joint Propulsion Conference, AIAA-2016-4829, doi:10.2514/6.2016-4829, Salt Lake City, UT, Jul 25-27, 2016.

${ }^{11}$ Kamhawi, H., et al., "Performance, Facility Pressure Effects, and Stability Characterization Tests of NASA's Hall Effect Rocket with Magnetic Shielding Thruster", 52nd AIAA/ASME/SAE/ASEE Joint Propulsion Conference, AIAA-2016-4826, doi:10.2514/6.2016-4826, Salt Lake City, UT, Jul 25-27, 2016.

${ }^{12}$ Huang, W., Kamhawi, H., Myers, J. L., Yim, J. T., and Neff, G., "Non-Contact Thermal Characterization of NASA's HERMeS Hall Thruster", 51 st AIAA/ASME/SAE/ASEE Joint Propulsion Conference, AIAA-2015-3920, doi:10.2514/6.2015-3920, Orlando, FL, Jul 27-29, 2015.

${ }^{13}$ Myers, J. L., Kamhawi, H., Yim, J. T., and Clayman, L., "Hall Thruster Thermal Modeling and Test Data Correlation", 52nd AIAA/ASME/SAE/ASEE Joint Propulsion Conference, AIAA-2016-4535, doi:10.2514/6.2016-4535, Salt Lake City, UT, Jul 2527, 2016.

${ }^{14}$ Huang, W., Kamhawi, H., Haag, T. W., Lopez Ortega, A., and Mikellides, I. G., "Facility Effect Characterization Test of NASA's HERMeS Hall Thruster", 52nd AIAA/ASME/SAE/ASEE Joint Propulsion Conference, AIAA-2016-4828, doi:10.2514/6.2016-4828, Salt Lake City, UT, Jul 25-27, 2016.

${ }^{15}$ Peterson, P. Y., et al., "NASA's HERMeS Hall Thruster Electrical Configuration Characterization ", 52nd AIAA/ASME/SAE/ASEE Joint Propulsion Conference, AIAA-2016-5027, doi:10.2514/6.2016-5027, Salt Lake City, UT, Jul 2527, 2016.

${ }^{16}$ Williams, G. J., et al., "Wear Testing of the HERMeS Thruster", 52nd AIAA/ASME/SAE/ASEE Joint Propulsion Conference, AIAA-2016-5025, doi:10.2514/6.2016-5025, Salt Lake City, UT, Jul 25-27, 2016.

${ }^{17}$ Huang, W., et al., "Plasma Plume Characterization of the HERMeS during a 1722-hr Wear Test Campaign", 35th International Electric Propulsion Conference, 2017-307, Atlanta, GA, Oct 8-12, 2017.

${ }^{18}$ Chaplin, V. H., et al., "Laser Induced Fluorescence Measurements of the Acceleration Zone in the $12.5 \mathrm{~kW}$ HERMeS Hall Thruster", 35th International Electric Propulsion Conference, 2017-229, Atlanta, GA, Oct 8-12, 2017.

${ }^{19}$ Polk, J. E., et al., "Inner Front Pole Erosion in the $12.5 \mathrm{~kW}$ HERMeS Hall Thruster Over a Range of Operating Conditions", 35th International Electric Propulsion Conference, 2017-409, Atlanta, GA, Oct 8-12, 2017.

${ }^{20}$ Kamhawi, H., et al., "Performance, Stability, and Plume Characterization of the HERMeS Thruster with Boron Nitride Silica Composite Discharge Channel", 35th International Electric Propulsion Conference, 2017-392, Atlanta, GA, Oct 8-12, 2017.

${ }^{21}$ Williams, G. J., et al., "Wear Trends of the HERMeS Thruster as a Function of Throttle Point", 35th International Electric Propulsion Conference, 2017-207, Atlanta, GA, Oct 8-12, 2017.

${ }^{22}$ Peterson, P. Y., et al., "Reconfiguration of NASA GRC's Vacuum Facility 6 for Testing of Advanced Electric Propulsion System (AEPS) Hardware", 35th International Electric Propulsion Conference, 2017-028, Atlanta, GA, Oct 8-12, 2017.

${ }^{23}$ Jorns, B. A., Goebel, D. M., and Hofer, R. R., "Plasma Perturbations in High-Speed Probing of Hall Thruster Discharge Chambers: Quantification and Mitigation", 51st AIAA/ASME/SAE/ASEE Joint Propulsion Conference, AIAA-2015-4006, doi:10.2514/6.2015-4006, Orlando, FL, Jul 27-29, 2015.

${ }^{24}$ Yim, J. T. and Burt, J. M., "Characterization of Vacuum Facility Background Gas Through Simulation and Considerations for Electric Propulsion Ground Testing", 51st AIAA/ASME/SAE/ASEE Joint Propulsion Conference, AIAA-2015-3825, doi:10.2514/6.2015-3825, Orlando, FL, Jul 27-29, 2015.

${ }^{25}$ Huang, W., Smith, T. B., and Gallimore, A. D., "Obtaining Velocity Distribution using a Xenon Ion Line with Unknown Hyperfine Constants", 40th AIAA Plasmadynamics and Laser Conference, AIAA-2009-4226, doi:10.2514/6.2009-4226, San Antonio, Texas, Jun 22-25, 2009.

${ }^{26}$ Huang, W., Drenkow, B., and Gallimore, A. D., "Laser-Induced Fluorescence of Singly-Charged Xenon Inside a 6-kW Hall Thruster", 45th AIAA/ASME/SAE/ASEE Joint Propulsion Conference \& Exhibit, AIAA-2009-5355, doi:10.2514/6.2009-5355, Denver, CO, Aug 2-5, 2009. 
${ }^{27}$ Durot, C. J., Georgin, M. P., and Gallimore, A. D., "Time-Resolved Laser-Induced Fluorescence Measurements in the Plume of a 6-kW Hall Thruster", 34th International Electric Propulsion Conference, 2015-399, Kobe, Japan, Jul 4-10, 2015.

${ }^{28}$ Jorns, B. A., et al., "Mechanisms for Pole Piece Erosion in a 6-kW Magnetically-Shielded Hall Thruster", 52nd AIAA/ASME/SAE/ASEE Joint Propulsion Conference, AIAA-2016-4839, doi:10.2514/6.2016-4839, Salt Lake City, UT, Jul 25$27,2016$.

${ }^{29}$ Sekerak, M. J., Hofer, R. R., Polk, J. E., Jorns, B. A., and Mikellides, I. G., "Wear Testing of a Magnetically Shielded Hall Thruster at 2000 s Specific Impulse", 34th International Electric Propulsion Conference, 2015-155, Kobe, Japan, Jul 4-10, 2015. 